\title{
The bats of the Rio Martino Cave, North West Italy (Mammalia Chiroptera)
}

\author{
Roberto Toffoli
}

CHIROSPHERA, Associazione per lo Studio e la Tutela dei Chirotteri e l'Ambiente, Via Tetti Barbiere 11, 10026 Santena, Torino, Italy; email: rtoffoli@iol.it

\section{ABSTRACT}

KEY WORDS

\begin{abstract}
We present the results of a monitoring of the hibernating bats (Mammalia Chiroptera) in the Rio Martino Cave (North West Italy) and a survey of swarming activity. In total, 13 species of cave-dwelling bats were detected. During winter monitoring, 12 species of bats were recorded. The most abundant bat was Barbastella barbastellus (Schreber, 1774) which represents $91.5 \%$ of the total hibernating bats documented in the cave, and its number has increased significantly, reaching a maximum of 410 bats in the winter of 2013-2014. A significant positive trend in population increase was also observed for Myotis emarginatus (E. Geoffroy Saint-Hilaire, 1806). Between 2009 and 2010, a total of 354 bats belonging to 9 species were captured, thus confirming swarming activity for Myotis emarginatus and the presence of M. bechsteinii (Kuhl, 1817). The results confirm the importance of the Rio Martino Cave for the conservation of cave-dwelling bats in the Italian western Alps.
\end{abstract}

Mammalia; Chiroptera; monitoring, hibernating; swarming; Italian Alps.

\section{INTRODUCTION}

The importance of the Rio Martino Cave for the bats has long been known, but due to the lack of studies on bats, the historical information available in this regard is fragmented. In the early 1960s, the cave was a target location for a ringing activity carried out by the Bats Ringing Center of the Italian Speleological Society. Unfortunately it is difficult, if not impossible, to use the chiropterological information gathered during this experience, since the overall reports published are incomplete and, in part, contradictory. However, from the available sources (Dinale, 1965; Martinotti, 1968), it is clear which individuals in the winter of 1960-61 were captured in the cave and ringed or collected as spe- cimens for museum destinations. These individuals belonged to at least 4 species of bats: Rhinolophus hipposideros (Bechstein, 1800) (at least one specimen), Myotis blythii Tomes, 1857 and/or M. myotis Borkhausen, 1797 (at least 4 specimens), Myotis emarginatus (E. Geoffroy Saint-Hilaire, 1806) (at least 2 specimens), and Barbastella barbastellus (Schreber, 1774) (at least 24 specimens: 11 ringed on 8.XII.1960, of which 3 were recaptured on 6.I.1961, when a further 11 bats were ringed and 2 specimens were collected for the Doria Museum of Genoa, Italy). Subsequently, chiropterological information for the cavity was no longer available until the 1990s.

Since the winter of 1991-1992, the cave is regularly monitored to assess the number and the trend 
of wintering bats and is subject to specific surveys with the aim of verifying the bats' annual presence and their use of the cave as a swarming site. Winter monitoring was partially financed in the 2004-2009 period by the Biodiversity and Natural Area Office of Piedmont Region (Debernardi et al., 2010).

The aim of this work is to provide a summary of current knowledge about the bats in the cave of Rio Martino based on records collected during twenty-eight years of survey and bat monitoring, evaluating their richness, population trends, and use of this habitat.

\section{MATERIAL AND METHODS}

\section{Study area}

The cave of Rio Martino (Crissolo, Cuneo, North West Italy, $44^{\circ} 42.017^{\prime} \mathrm{N}-7^{\circ} 8.881^{\prime} \mathrm{E}$ ) is the most important natural underground cavity of the Italian Cottian Alps with an entrance 1,530 meters above sea level, a development of 2,905 metres and a difference level of 191 metres $(+174,-17)$ (AGSP
2010). The entrance is located on the right side of the Po Valley (Fig. 1), in an area characterized by mixed deciduous forests and Larix decidua Mill. The cave is designated as Special Areas of Conservation (SAC) IT1160037 and is currently managed by the Natural Park of Monviso.

The average temperature in the cave it is approximately $4^{\circ} \mathrm{C}$ with a humidity close to $100 \%$. Daily temperature fluctuations are very slight, of the order of $0.02^{\circ} \mathrm{C}$, and there is continuous unidirectional ventilation with a speed between 5 and 48 meters per minute (Badino, 2008).

The troglobiotic fauna is rather poor and typical of cold caves and is at a high altitude with the presence of Diplopoda, such as Crossoma semipes Strasser, 1958, and predatory Opilions, such as Ischyropsalis cfr. alpinula Martens, 1978 (Lana, 2001).

\section{Bat sampling}

The methods used to survey and monitor the bats in the Rio Martino cave refer to direct counts

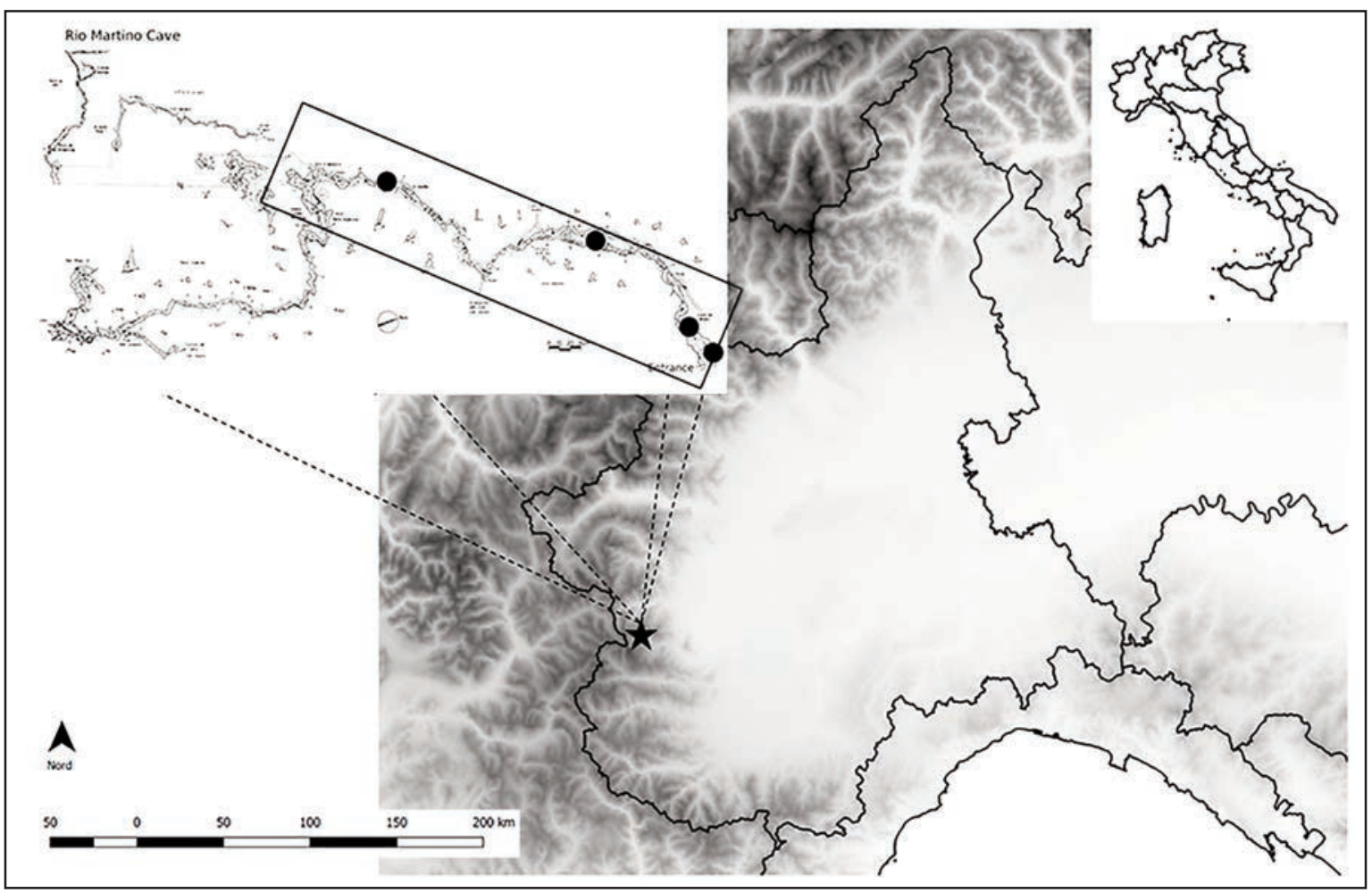

Figure 1. Study area. Star: localization of the cave; rectangle: part of the cave being monitored; black dots: temperature/humidity data logger position. 
of hibernating individuals and to captures with mist-nets and harp-traps in late summer-early autumn. During the hibernation phase, individuals were counted directly on site, or in the case of large and aggregated groups, with photographic images taken from the site. In order to minimize the disturbance, a single annual survey beginning from winter 1991-1992 to winter 2018-2019 was generally carried out on a central date of the lethargy period (from 15 December to 15 February, preferably between the end of December and mid-January). In some winters, two counts were carried out and, in such cases, the count with the largest number of bats was used. From June 2009 to May 2010, in addition to monitoring hibernating bats, monthly visits were carried out to verify the annual phenology. All counts were always made in the same portion of the cave (from the entrance to the "Pissai" cascade) to allow comparison.

During the visits, all bats were identified based on differences in morphology at the species level, when possible (Nyssen, 2015), in some cases with the help of $10 \times 42$ binoculars. In cases where the species could not be identified due to intrinsic difficulties, the genus or species group was used instead.

The number of hibernating bats during the last fourteen winters has been correlated with the average temperature of the month preceding the count in order to verify correlations between meteorological variables. The data relating to the temperatures have been obtained from the weather stations of ARPA Piemonte (Regional Agency for Environmental Protection) located at Crissolo (Cuneo) available on https://www.arpa.piemonte.it/rischinaturali /accesso-ai-data/annali_meteoidrologici/annals hydro-meteorological/bank-data-meteorologica. html.

In 2009 and 2010, captures were also carried out to verify the use of the cave as a swarming site. The captures were made during the nights of $16-17 \mathrm{Au}-$ gust, 18-19 September 2009 and 15-16 September 2010, using a harp trap at the entrance of the cave which was active from sunset until 04:00. All individuals captured were identified to species level, and the sex, reproductive status, and age according

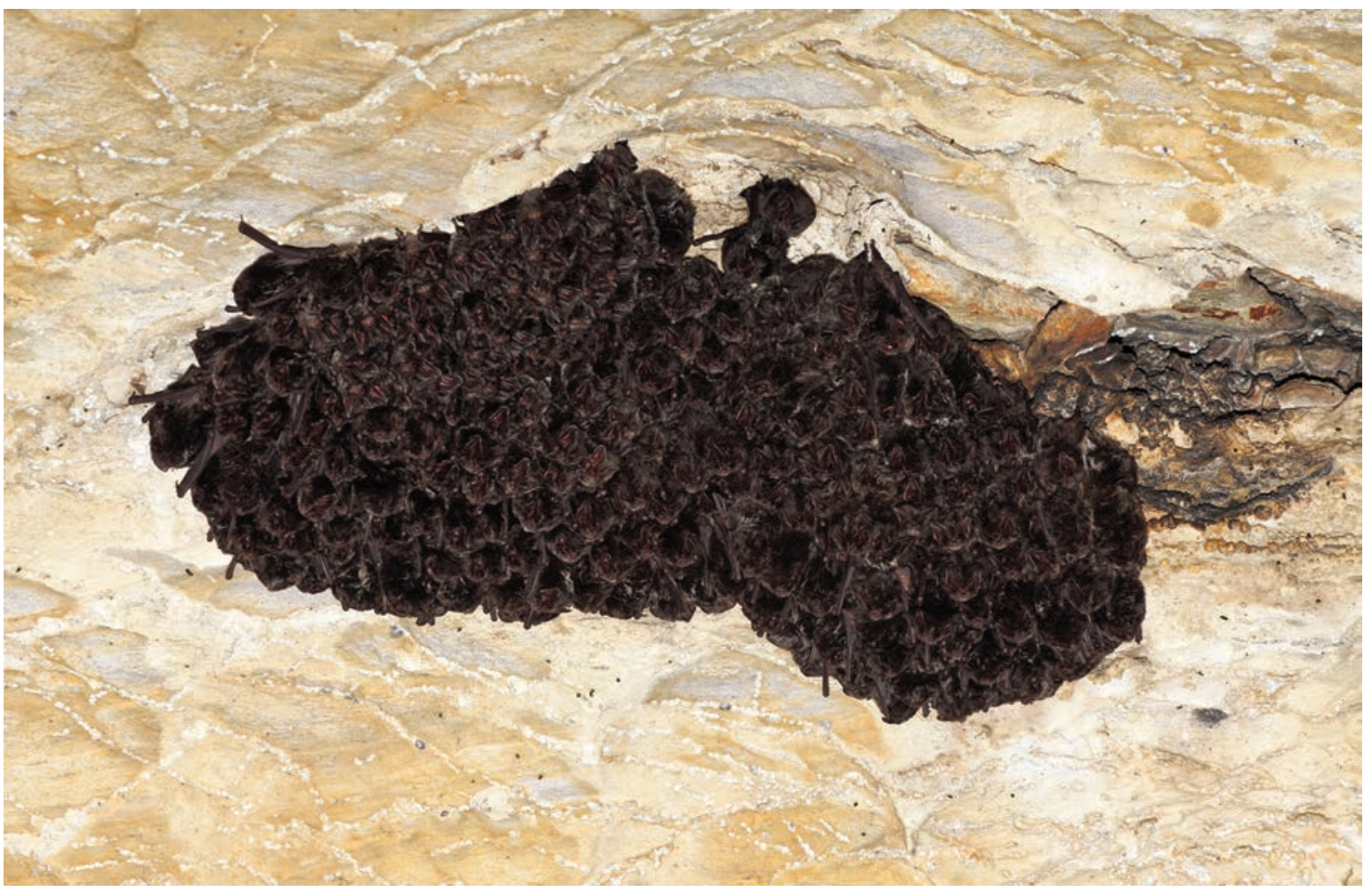

Figure 2. Cluster of 205 Barbastella barbastellus in winter 2012-2013 (cave of Rio Martino, Crissolo, Cuneo, North West Italy). 


\begin{tabular}{|c|c|c|c|c|c|c|c|c|c|c|c|c|c|c|}
\hline 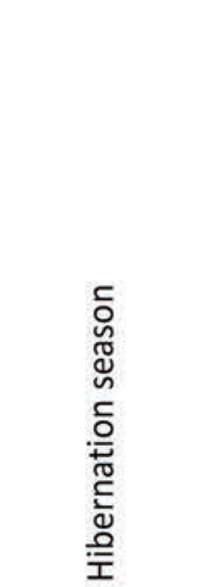 & 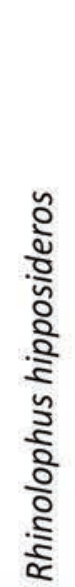 & 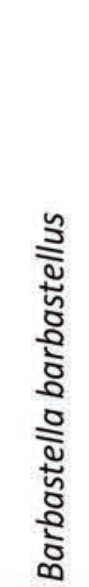 & 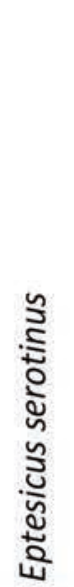 & 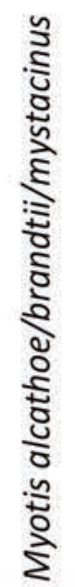 & 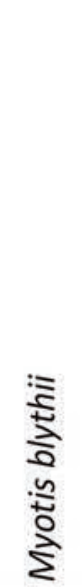 & 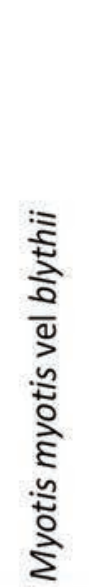 & 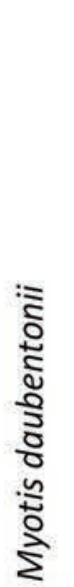 & 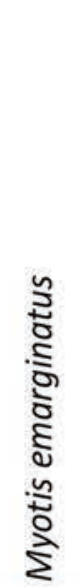 & 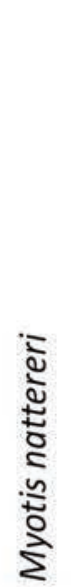 & 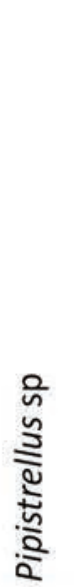 & 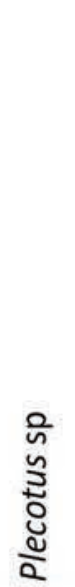 & 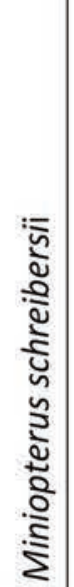 & 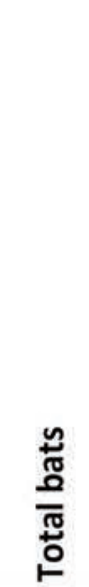 & 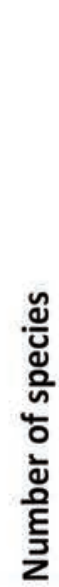 \\
\hline 1991/1992 & 1 & 7 & 1 & & 1 & 6 & & 2 & & 1 & & & 19 & 7 \\
\hline $1992 / 1993$ & & 10 & & & 1 & 5 & 1 & 2 & & & & & 19 & 5 \\
\hline $1993 / 1994$ & & 11 & & & 1 & 8 & & 1 & & & & & 21 & 4 \\
\hline $1994 / 1995$ & & 10 & & & 2 & 9 & & 1 & & & & & 22 & 4 \\
\hline $1995 / 1996$ & & 10 & & & 1 & 4 & & 1 & 1 & & 1 & & 16 & 4 \\
\hline 1996/1997 & & 17 & & & 3 & 6 & & 1 & & & 1 & & 28 & 5 \\
\hline $1997 / 1998$ & & 18 & 1 & & 2 & 7 & & 2 & 1 & & & & 29 & 5 \\
\hline 1998/1999 & & 16 & 1 & & 2 & 5 & 1 & 2 & & & & & 27 & 6 \\
\hline $1999 / 2000$ & & 21 & & & 2 & 6 & & 2 & 1 & & & & 30 & 4 \\
\hline $2000 / 2001$ & & 41 & & & 2 & 12 & & 4 & & & & & 59 & 4 \\
\hline $2001 / 2002$ & & 44 & & & 2 & 2 & 1 & 5 & & & & & 54 & 5 \\
\hline $2002 / 2003$ & & 76 & & & 1 & 11 & & 2 & & & & & 90 & 4 \\
\hline $2003 / 2004$ & & 82 & & & 2 & 5 & & 1 & & & & & 90 & 4 \\
\hline $2004 / 2005$ & & 129 & & & 5 & 19 & 1 & 2 & & & & & 156 & 5 \\
\hline $2005 / 2006$ & & 178 & 1 & & 8 & 2 & 4 & 9 & & & & & 202 & 6 \\
\hline $2006 / 2007$ & & 183 & & 2 & 7 & 3 & 3 & 6 & & & & & 204 & 6 \\
\hline $2007 / 2008$ & & 272 & & & 5 & 2 & & 3 & & & & & 282 & 4 \\
\hline $2008 / 2009$ & & 295 & & & 6 & 2 & 1 & 3 & & & & & 307 & 5 \\
\hline $2009 / 2010$ & & 375 & 1 & & 10 & 2 & 1 & 1 & & & & & 390 & 6 \\
\hline $2010 / 2011$ & & 380 & & & 4 & 3 & & 4 & & & & & 380 & 4 \\
\hline $2011 / 2012$ & & 367 & & & 1 & 9 & 3 & 2 & & & 1 & & 383 & 6 \\
\hline $2012 / 2013$ & & 399 & 1 & & 3 & 8 & & 6 & & & & & 417 & 5 \\
\hline $2013 / 2014$ & & 410 & 1 & & 4 & 3 & & 5 & & & 1 & & 424 & 6 \\
\hline $2014 / 2015$ & & 380 & 1 & & 3 & 1 & & 5 & & & 1 & & 391 & 6 \\
\hline $2015 / 2016$ & 1 & 170 & 1 & 1 & 7 & 10 & & 3 & & & & & 193 & 7 \\
\hline $2016 / 2017$ & & 293 & 1 & & 9 & 4 & & 7 & & & & & 314 & 5 \\
\hline $2017 / 2018$ & & 193 & & & 10 & 7 & & 19 & & 1 & & 1 & 231 & 6 \\
\hline $2018 / 2019$ & & 195 & & & 4 & 9 & 1 & 18 & & & & 1 & 228 & 6 \\
\hline
\end{tabular}

Table 1. Number of hibernating bats in Rio Martino Cave. 
to the ossification of the phalanges was recorded (Dietz \& Von Helversen, 2004; Brunet-Rossini \& Wilkinson, 2009; Haarsma, 2008). Bats were subsequently released after being marked on their toes with a non-toxic paint to check for possible recaptures.

The captures were made under permission of the Italian Ministry for the Environment, Land and Sea (DPN/2008/0001053; DPN/2010/0011879).

Temperature and humidity parameters of the cave were monitored from July 2009 to September 2011, through the placement of 4 data loggers Testo $174 \mathrm{~T}$ (Fig. 1) set to record data every hour.

\section{RESULTS}

Surveys and monitoring, conducted over the years, allowed to detect the presence of 13 bats species in the cave.

During the winter monitoring, presence of 12 species of bats was detected with a maximum of 7 species and a minimum of 4 for the hibernation period (Table 1). Four species were found on every winter: Barbastella barbastellus, Myotis blythii, $M$. emarginatus, and M. myotis vel blythii. One species was detected for ten winters, Eptesicus serotinus (Schreber, 1774), one was detected for nine winters, Myotis daubentonii (Kuhl, 1817), while the others were recorded for no more than five winters.

The most abundant bat was Barbastella barbastellus which represents $91.5 \%$ of the total hibernating bats counted in the cave (mean $\pm \mathrm{SD}=162 \pm$ 151 ), and the number of individuals has increased significantly $(\mathrm{Rs}=0.90, \mathrm{p}<0.001)$ reaching a maximum of 410 bats during the winter of 2013-2014 and then decreasing (Table 1). This species is observed in hibernation as isolated individuals or as large clusters ( $>200$ bats) (Fig. 2). The annual variations in the number of bats belonging to this species are inversely correlated with the average temperature values of the month before the count (Fig. 3), and this correlation is significant. (Wilcoxon test $Z=-3.29, p<0.001$ ). As for the other species observed every year, there is a significant positive trend $(\mathrm{Rs}=0.66, \mathrm{p}<0.001)$ only for Myotis emarginatus, while for large Myotis (M. blythii and $M$. myotis) there is no defined trend.

The location of the different species of bats in the cave is influenced by the characteristics of the air, including temperature and humidity. Barbastella barbastellus is present from the entrance to the first half of the monitored part of the cave. In this sector, the temperatures show an average value in the period from 15 December-15 February of 0.7 ${ }^{\circ} \mathrm{C}( \pm$ SD 1.3$)$ with an average humidity of $84.2 \%$ ( \pm SD 18.7), with wide fluctuations (temperature min. $-1.5 \max 3.5$, humidity $\min .42 .3 \% \max$ 99.9\%). In this part of the cave, the species Eptesicus serotinus, Pipistrellus sp., Plecotus sp., and Miniopterus schreibersi (Kuhl, 1817) were also observed.

The large Myotis, Rhinolophus hipposideros, Myotis emarginatus, and the other small Myotis are observed in the deepest part of the cave where the temperature is on average higher and constant (mean $\pm \mathrm{SD}=6.2 \pm 0.5$, min. $5.7 \max 7.1$ ) with a high mean humidity of $95.0 \%$ ( \pm SD 3.5).

Monthly counts made between 2009 and 2010 showed the presence of bats in every month of the year with the exception of August (Table 2). Three species (Barbastella barbastellus, Eptesicus serotinus, and Myotis daubentonii) were detected only during the hibernation period in late autumn and early spring. As for Barbastella barbastellus, their presence was detected from October to March, with a peak in January and February. Only the large Myotis (M. myotis and M. blythii) were observed every month, with the exception of August, while Myotis emarginatus was also detected in the spring during the months of April and May, as well as September and in the winter.

The captures made in 2009 and 2010 detected a total of 354 bats belonging to 9 species (Table 3). Most of the captured bats were male, while only 57 were females (16.1\%). The majority of males showed evident reproductive traits, with swollen testicles ( $68.2 \%$ of captured males). The most abundant species of all the three capture sessions was Myotis emarginatus ( $71.5 \%$ of the total), followed by Myotis daubentonii (14.7\%) and Barbastella barbastellus $(8.5 \%)$. The hourly trend of the captures showed a peak between 22:00 and 01:00 with variations between the three sessions (Fig. 4).

\section{DISCUSSION}

The results confirm the importance of the Rio Martino cave for the bats. The 12 species detected 
in hibernation, a number which could be higher as unidentified species could hide within these groups, represent the highest number of species for a winter site in Italy (GIRC, 2004). Of particular importance is the high number of Barbastella barbastellus in hibernation. The Rio Martino cave is the most important hibernation site for this species in Italy, since there are only six wintering sites currently known of which only one has no more than 100 individuals (GIRC, 2004). The long-term trend observed for this species corresponds to what was observed during the winter in other European countries (e.g., Poland, Slovakia) where stable or increasing trends were observed (Lesiński et al., 2005, 2011; Uhrin et al., 2010) or more generally significant positive trends with an average annual increase of 4\% in Europe are occurring (Van der Meij et al., 2015). The decrease observed from the winter of 2014-2015 is difficult to explain. It is however evident that the number of Barbastella barbastellus observed in the last fourteen winters is correlated with the average temperature of the month preceding the count, and the last three winters have been characterized by fairly high temperatures compared to the average (https://www.arpa.piemonte.it/rischinaturali/accesso-ai-data/annali_meteoidrologici/ annals hydro-meteorological/bank-data-meteorologica.html). Also, for Myotis emarginatus the hibernating trend corresponds to what was generally observed in Europe (Van der Meij et al., 2015). For the other species, it is not possible to make any consideration about the trends observed due to the limited number of individuals observed.

Of some interest are the observations of Rhinolophus hipposideros and Miniopterus scheribersii hibernating in the cave. Rhinolophus hipposideros was recorded as present in the Rio Martino cave during the 1960s (Martinotti, 1968; Sindaco et al., 1992) and observed in hibernation in the winter of 1991-1992. Subsequently, the species was no longer detected until the winter of 2015-2016, probably as a consequence of the increase in the number of hibernating bats observed at other sites in the province of Cuneo (Toffoli, 2005). Miniopterus schreibersi is a rare species in Piedmont, and to date, the only locality where the species has been recorded is a gypsum mine in the province of Cuneo at 210 meters above sea level where arguably the species has reproduced once (Boano \& Curletti, 1974) and where it is currently present with a single

\begin{tabular}{|c|c|c|c|c|c|c|c|c|}
\hline & 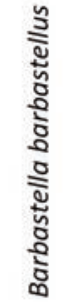 & 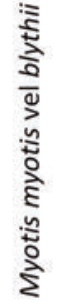 & 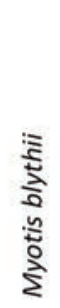 & 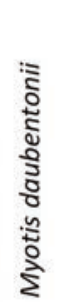 & 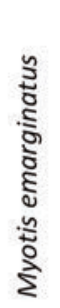 & 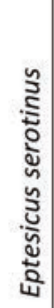 & 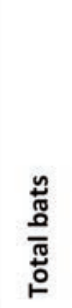 & 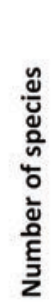 \\
\hline June & & 1 & 1 & & & & 2 & 2 \\
\hline July & & 1 & & & & & 1 & 1 \\
\hline August & & & & & & & 0 & 0 \\
\hline September & & 4 & 1 & & & & 5 & 2 \\
\hline October & 15 & 2 & 2 & & 1 & & 20 & 4 \\
\hline November & 35 & 2 & 2 & & & & 39 & 3 \\
\hline December & 193 & 1 & 9 & & 1 & 1 & 205 & 5 \\
\hline January & 375 & 2 & 10 & 1 & 1 & 1 & 390 & 6 \\
\hline February & 380 & 4 & 8 & 1 & 3 & 1 & 397 & 6 \\
\hline March & 38 & 1 & 3 & & 2 & 1 & 45 & 5 \\
\hline April & & 1 & & & 1 & & 2 & 2 \\
\hline May & & 1 & & & 1 & & 2 & 2 \\
\hline
\end{tabular}

Table 2. Number of bats counted monthly from 2009 to May 2010.

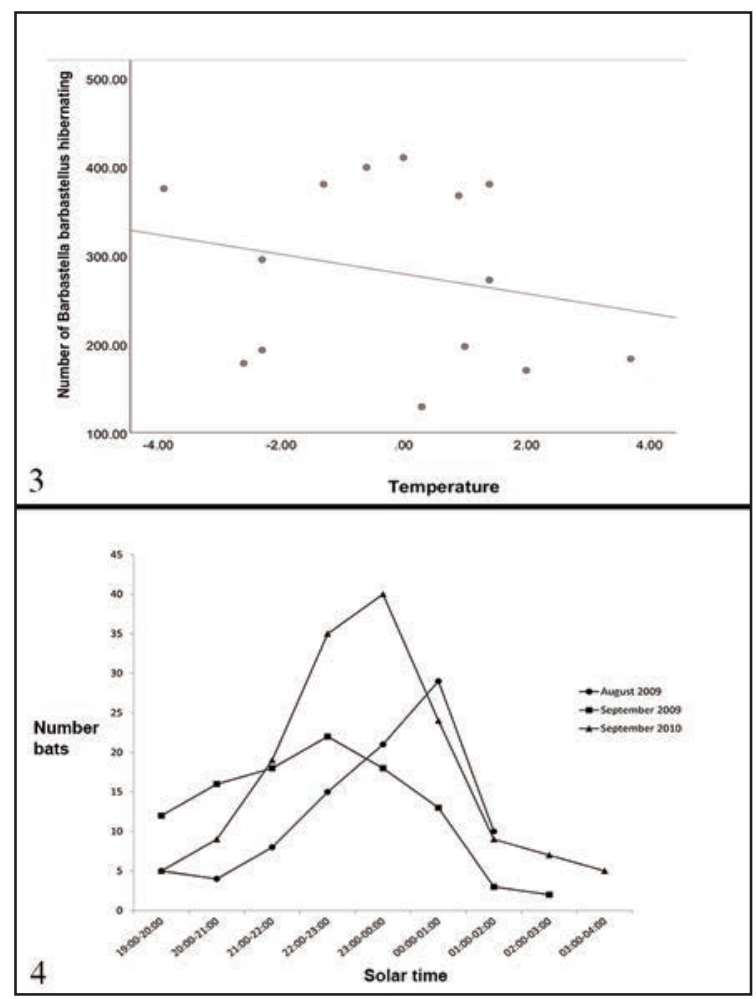

Figure 3. Correlation between the number of Barbastella barbastellus hibernating and the average external temperature of the cave in the month preceding the count. Figure 4. Hourly variations in the number of bats captured at the entrance to the cave. 


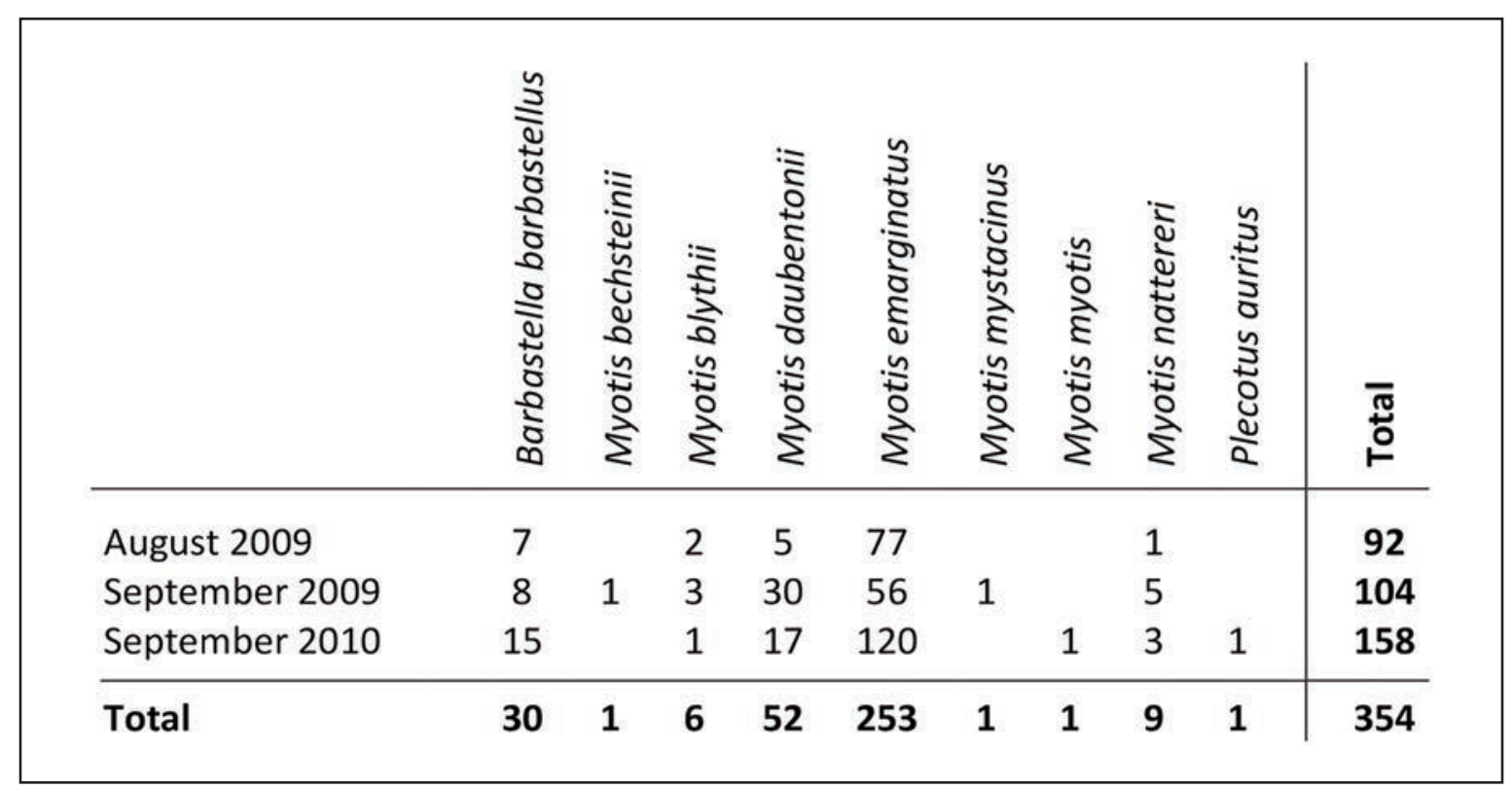

Table 3. Number of bats captured at the entrance of the cave.

specimen in autumn and winter (Debernardi et al., 2010; Toffoli, unpublished data). The winter observations in the Rio Martino cave represents a second site of presence for the species in Piedmont and is one of the highest altitude observations in Italy. The species is reported in Italy up to 1,050 meters above sea level on the central Apennines (Lanza, 2012), although there are reports of its presence up to about 1,500 meters in Austria (Spitzenberger, 1981) and up to 1,630 meters in the French Alps (Drousie \& Cosson, 2016).

As for the characteristics of temperature and humidity where the different species of bats have been detected in the cave, these coincide with the ranges available in bibliography (Bogdanowicz \& Urbańczyk, 1983; Daan \& Wichers, 1968; Webb et al., 1996) with values comprised between $-3.0^{\circ}$ and $6.5^{\circ}$ for the most cold-tolerant species (e.g., Barbastella barbastellus) and between $5.0^{\circ}$ and 10.5 for those mostly related to higher temperatures (e.g., Myotis emarginatus) (Webb et al., 1996).

The correlation between the number of hibernating Barbastella barbastellus and the average temperatures of the month preceding the count can be partly explained by the greater flight activity and the possible movements between the different roosts. The external temperature can, in fact, stimulate the activity of the bats in hibernation making them change the roost and shelter, in particular for the individuals who hibernate closer to the entrances of the caves where the microclimatic variations are greater (Daan, 1973). This may suggest movements of Barbastella barbastellus wintering in roosts exposed to climatic variations towards the cave of Rio Martino during periods of lowering temperatures.

The presence of bats through all months of the year increases the conservation value of the cave. The absence of bats observed in daytime rest during the month of August is probably not real, but linked to the difficulty of observing the few individuals often hidden in deep crevices of the rock. The presence of bats in this month is, in fact, confirmed by their capture at the cave entrance.

The activity detected in the late summer trough captures, the hourly variations, and the composition in age and sex classes of the captured bats are consistent with those expected for swarming sites (Parsons et al., 2003, 2003a; Šuba et al., 2008). The number of species and individuals detected is high and is greater than any other known swarming sites in Piedmont (Debernardi et al., 2010; Toffoli \& Culasso, 2010). Bats detected during swarming correspond to the hibernating species with the exception of Myotis bechsteinii (Kuhl, 1817) which was not detected during winter counts. The absence of this species in winter can be explained by the behaviour of hiding 
in deep cavities making observation difficult (Groupe Chiroptères de la LPO Rhone-Alpes, 2014).

The results confirm the importance of the Rio Martino Cave for the conservation of bats, with at least 13 species detected, of which 12 were observed in hibernation. In particular, the cave has great importance at an Italian level for the wintering of Barbastella barbastellus, but it is also an important swarming site for all the other species living in the Italian western Alps. Last but not least, the cave plays an important role for the diurnal shelter of individuals during the spring and summer.

\section{ACKNOWLEDGEMENTS}

I thank all those who have helped and made the monitoring possible, in particular M. Calvini (San Remo, Imperia, Italy), P. Culasso (Santena, Torino, Italy), and the members of the Chirosphera Association (Torino, Italy). Thanks also to the Natural Park of Monviso (Saluzzo, Cuneo, Italy) for authorization to access the cave.

\section{REFERENCES}

AGSP, 2010. Atlante delle aree carsiche piemontesi. Vol.1. Regione Piemonte - Associazione Gruppi Speleologici Piemontesi, 296 pp.

Badino G., 2008. Micrometereologia delle grotte. I congresso DFG, Torino 2008, 150 pp.

Boano G. \& Curletti G., 1974. Prima segnalazione di Miniopterus scheribersii (Natt.) in Piemonte. Natura, Milano, 65: 254.

Bogdanowicz W. \& Urbańczyk Z., 1983. Some ecological aspects of bats hibernating in city of Poznań. Acta theriologica, 28: 371-385.

Brunet-Rossini A.K. \& Wilkinson G.S., 2009. Methods for age estimation and the study of senescence. In: Kunz T.H. \& Parson S. (Eds.), Bat ecological and behavioral methods for the study of bats. Johns Hopkins University Press, Baltimore, 315-325.

Daan S., 1973. Activity during natural hibernation in three species of vespertilionid bats. Netherlands Journal of Zoology, 23: 1-71.

Daan S. \& Wichers H.J., 1968. Habitat selection of bats hibernating in a limestone cave. Zeitschrift für Säugetierkunde, 33: 262-287.

Debernardi P., Patriarca E. \& Toffoli R., 2010. Monitoraggio delle colonie di chirotteri riproduttive e svernanti di particolare interesse conservazionistico presenti in Piemonte e dati preliminari sull'attivita' di swarming. Rapporto 2009/2010. Parco naturale dei Laghi di Avigliana.

Dietz C. \& Von Helversen O., 2004 . Illustrated identification key to the bats of Europe. Electronic Publication Version 1.0. Released 15.12.2004. Tuebingen \& Erlangen, Germany, 72 pp. https://doi.org/10. 13140/RG.2.1.3908.5606

Dinale G., 1965. Studi sui chirotteri italiani: IV. Osservazioni su Myotis emarginatus, Myotis capaccinii, Nyctalus noctula, Plecotus sp. e Barbastella barbastellus in alcune regioni italiane. Doriana, suppl. Annali del Museo civico di storia naturale di Genova, 4 (156): 1-5.

Drousie M. \& Cosson M., 2016. Le Minioptère de Schreibers Miniopterus schreibersii. In: LPO, PACA, GECEM \& GCP, Les Mammifères de Provence- Cote d'Azur, Biotope, Mèze, pp. 156157.

GIRC, 2005. The Italian bat roost project: a preliminary inventory of sites and conservation perspectives. Hystrix, the Italian Journal of Mammalogy, 15: 5568. https://doi.org/10.4404/hystrix-15.2-4336

Groupe Chiroptères de la LPO Rhone-Alpes, 2014. Les chauves souris de Rhone-Alpes. LPO Rhone-Alpes, Lyon, $478 \mathrm{pp}$.

Haarsma A.J., 2008. Manual for assessment of reproductive status, age and health in european vespertilionid bats. Electronic publication, Version 1, First released 12-09-2008. Hillegom, Holland.

Lana E., 2001. Biospeleologia del Piemonte. Atlante fotografico sistematico. Regione Piemonte - Associazione Gruppi Speleologici Piemontesi, 260 pp.

Lanza B., 2012. Fauna d'Italia. Mammalia V. Chiroptera. Calderini Editore, Bologna, 47, 786 pp.

Lesinski G., Fuszara E., Fuszara M., Jurczyszyn M. \& Urbanczyk, Z., 2005. Long-term changes in the numbers of the barbastelle Barbastella barbastellus in Poland. Folia Zoologica, 54: 351-358.

Lesiński G., Ignaczak M. \& Kowalski M., 2011. Increasing bat abundance in a major winter roost in central Poland over 30 years. Mammalia 75: 163-167. https://doi.org/10.1515/mamm.2011.003

Martinotti A., 1968. Elenco sistematico e geografico della fauna cavernicola del Piemonte e della Valle d'Aosta. Rassegna Speleologica Italiana, 20: 1-32.

Nyssen P., 2015. Mémo pour la détermination des chauves-souris en hiver. Plecotus-Natagora. Italian version translated and adapted by Culasso P. \& Toffoli R., 2017. Chirosphera Associazione per lo studio e la tutela dei Chirotteri e l'ambiente, Torino, $21 \mathrm{pp}$.

Parsons K.N., Jones G. \& Greenaway F., 2003. Swarming activity of temperate zone microchiropteran bats: effects of season, time of night and weather conditions. Journal of Zoology, 261: 257-264. https://doi. org/10.1017/S0952836903004199 
Parsons K.N., Jones G., Davidson-Watts I. \& Greenaway F., 2003a. Swarming of bats at underground sites in Britain - implications for conservation. Biological Conservation, 111: 63-70. https://doi.org/10.1016/ S0006-3207(02)00250-1

Sindaco R., Baratti N. \& Boano, G., 1992. Bats of Piedmont and the Aosta Valley (NW Italy) / I chirotteri del Piemonte e della Val d'Aosta. Hystrix, the Italian Journal of Mammalogy, 4: 1-40. https://doi.org/10. 4404/hystrix-4.1-3977

Spitzenberger F., 1981. Die Langfluegelfledermaus Miniopterus schreibersi (Kuhl, 1819) in Osterreich. Mammalia Austriaca 5. mitt. Abteilung für Zoologie am Landesmuseum Joanneum, 10: 139-156.

Šuba J., Vintulis V. \& Petersons G., 2008. Late summer and autumn swarming of bats at Sikspru caves in Gauja National Park. Acta Universitatis Latviensis, 745: 43-52.

Toffoli R., 2005. Il Rhinolophus hipposideros in provincia di Cuneo: status e distribuzione. Memorie del Museo della Riserva Naturale Orientata di Onferno, 2: 5-11.
Toffoli R. \& Culasso P., 2010. Utilizzo autunnale di siti sotterranei da parte della chirotterofauna in Piemonte e definizione del loro ruolo ecologico (Mammalia, Chiroptera). Rivista piemontese di Storia naturale, 31: 265-278.

Uhrin M., Benda P., Obuch J. \& Urban P., 2010. Changes in abundance of hibernating bats in central Slovakia (1992-2009). Biologia, 65: 349-361. https://doi.org/ 10.2478/s11756-010-0020-Z

Van der Meij T., Van Strien A. J., Haysom K. A., Dekker J., Russ J., Biala K., Bihari Z., Jansen E., Langton S., Kurali A., Limpens H., Meschede A., Peterson G., Presetnik P., Pruger J., Reiter G., Rodrigues L., Schorcht W., Uhrin M. \& Vintulis V., 2015. Return of the bats? A prototype indicator of trends in European bat populations in underground hibernacula. Mammalian Biology, 80: 170-177. http://dx.doi.org/ 10.1016/j.mambio.2014.09.004

Webb P.I., Speakman J.R. \& Racey P.A., 1996. How hot is a hibernaculum? A review of the temperatures at which bats hibernate. Canadian Journal of Zoology, 74: 761-765. 
